\title{
0 ato(r) responsável: 0 atuador da Terreira da Tribo
}

\section{The act(or) responsible: the actuator of the Terreira da} Tribo

Andrea Paris ${ }^{1}$ 


\section{Resumo}

Este artigo procura aproximar o conceito de atuador, explorado pela Tribo de Atuadores Ói Nóis Aqui Traveiz, da proposta de Ato Responsável, desenvolvido pelo pesquisador russo Mikhail Bakhtin. Para isso, relata a trajetória do termo atuador no teatro Oficina e o seu desenvolvimento posterior na Tribo de Atuadores e também descreve o ato responsável, considerado pelo autor russo como um ato em resposta à alguma necessidade ou questão do mundo. Serão expostos alguns princípios artísticos, políticos e pedagógicos que refletem na postura ética que os atuadores da Tribo de Atuadores adotam em suas criações artísticas e podem ser considerados como atos responsáveis.

Palavras-Chave: Atuador; ato responsável "tribo" de Atuadores Ói Nóis Aqui Traveiz; ética.

\section{Abstract}

This article approaches the concept of actuator, operated by the Tribo de Atuadores Ói Nóis Aqui Traveiz, and the responsible act, developed by Russian researcher Mikhail Bakhtin around 1920. This article report the trajectory of the term actuator in Oficina Theater and its development later by Tribo de Atuadores. It describe also the responsible act considered by russian author as an act in response to any need or question the world. When the person perform the act he accepts the responsibility for participate and contribute to society. This article demonstrates that the actuator'Tribo de Atuadores performes responsible acts in their artistic creations.

Keywords: Actuador/atuador; action resonsible: "Tribo de Atuadores Ói Nóis Aqui Traveiz"; ethical.

ISSN: 1414.5731

Se o ator é um artista, ele é de todos os artistas o que em maior grau sacrifica sua pessoa ao ministério que exerce. Ele não pode dar nada se não se dá a si mesmo, não em efígie, mas de corpo e alma, e sem intermediário. Tanto sujeito quanto objeto, causa e fim, matéria e instrumento, sua criação é ele mesmo. (Jacques Coupeau)

O termo Atuador, no teatro, aparece no manifesto "Saldo para um Salto" do Teatro Oficina ${ }^{2}$ na década de 70 . Desde a sua criação, em 1958, o Oficina objetivava criar um trabalho revolucionário e o manifesto foi criado para formalizar e informar ao público dos novos ideais que o grupo idealizava. Entre os novos objetivos estava a busca por cativar o público que não tinha acesso ao teatro - como os trabalhadores das fábricas; a ocupação de outros espaços, além dos teatros convencionais; reformulação da cena de forma que fosse concebida como um testemunho, sem divisão entre palco e plateia, sem máscara, representação tradicional, maquiagem, fantasia ou qualquer elemento que pudesse produzir fascínio ou distanciasse o espectador da ação; a fim de cumprir todos estes objetivos, a denominação ator - componente do grupo - deveria ser substituída por Atuador e, a própria palavra "teatro" foi suprida por te-ato: "te uno a mim", "te obrigo a unir-se a mim" (Silva, 1981, p. 203). Para concretizar esses ideais, os atuadores fizeram algumas viagens pelo interior do país. Conviveram com aos moradores dos vilarejos por onde passaram, os ajudaram construir pontes, carregaram pedras, participaram de suas tarefas cotidianas (Silva, 1981, p. 204).

Quando o grupo voltou a São Paulo, ainda tomado pelas experiências da viagem e explorando os ideais descritos acima, montou a peça Gracias Señor, a partir de um argumento criado durante um encontro com o Living Theatre ${ }^{3}$, mas que ainda não havia sido desenvolvido. Como novas formas de propor a cena, a estrutura da peça era de um texto-roteiro, como na Commedia dell'Arte ${ }^{4}$, no qual eram definidas apenas algumas ações que conduziam o trabalho, possibilitando que os atuadores improvisassem em cena. Pensando o papel do público e do atuador no "te-ato", a direção não estava centralizada numa só pessoa, sendo que todos os componentes do grupo coordenavam todo o acontecimento teatral. O trabalho

era uma aula, em sete partes, de como transformar o espectador em atuador de 'te-ato'.. A vida renovada pela arte". [...] "Procuravam uma nova 'missão', que consistiria em lançr-se a uma investigacão em conjunto com as pessoas presentes na sala de espetáculos" (Silva, 1981, p. 206).

Depois dessa experiência, o Teatro Oficina seguiu questionando seu próprio trabalho, passou por diversas transições e o termo atuador acabou sendo repensado e abandonado. No entanto, a Tribo de Atuadores Ói Nóis Aqui Traveiz, de Porto Alegre, o toma para si na década de 1980 e o desenvolve até hoje. De acordo com a pesqui-

2 Teatro Oficina foi criado, em 1958, por José Celso Martinez Correa, Carlos Queiroz Telles e Hamir Haddad, em Săo Paulo e segue atuante até hoje. Living Theatre esteve no Brasil a convite do Officia, na década de 1970. For contra a participacąăo norte-americana na Guerra do Vietnâa, estimulando a de sobediência civil, na década de 1960. Luta pelo fim das fronteiras entre palco e plateia, das fronteiras entre arte e vida, atores e público, chamando o publico -

'Commedia dell'Arte: arte do século XVI, na região da França e Itália, que se caracterizava, principalmente, pela criação coletiva dos atores que improWSavam todo o espetaculo. Havia um roteiro pré-definido, o canevas, com (Pavis, 1999, p. 61) 
sadora Magdalena Toledo (2007, p. 109), os grupos não tinham ligação direta entre si, mas o gaúcho lia notícias sobre o trabalho do paulista. Segundo a autora, chegavam ao sul relatos das extraordinárias experiências do Te-ato. O roteiro Gracias Señor inspirou a formação e estruturação do grupo porto-alegrense. Criada em 1978 por Paulo Flores e Rafael Baião, a "tribo" se cristalizou no cenário teatral brasileiro como um dos grupos mais importantes do país, completando, atualmente, trinta e seis anos de atuação. Fundada em plena ditadura, tinha o objetivo de se tornar um ato artístico contra a opressão do governo. Com esse intuito, adotou uma postura questionadora ética em suas criações teatrais, em sua relação com o público, que tornou sua marca. Desde o início de seu estabelecimento, examinou todos os elementos do universo teatral, inclusive o conceito de ator, que parecia ser incompleto para os ideais da "tribo" e, por isso, as ações do Oficina dialogavam diretamente com os seus desejos e fo fonte de inspiração nos primeiros anos. Contudo, desenvolveu linguagem e pedagogia própria, rompendo com muitos conceitos da cena, influenciados não apenas pelo grupo paulista, mas por Antonin Artaud (1896-1948), Living Theatre, Jerzy Grotowski (1933-1999) e Eugênio Barba ${ }^{5}$ (1936). Inclusive, o conceito de atuador toma outras proporções e aprofundamentos:

Geralmente quando se pergunta o que é um atuador, respondemos que é o ator com o ativista politico. $O$ atuador deve ser lúcido e ambicionar mudar a sociedade, percebendo como urgente e primeira, a transformação de si mesmo. E o artista que sai do espaço restrito do palco e entra em contato com a comunidade da qual faz parte. Se envolve e compartilha de forma coletiva em todas as etapas da criação e produção do espetáculo. A ênfase e dada no processo contínuo de investigação, numa rotina árdua de trabalho, na busca de se fazer da cena um ato de entrega total, de teatralização total, de dispêndio absoluto. A subversão da ação e da palavra se dá num processo em que e o corpo inteiro que propõe livremente, por impulsos, vibrações, tensões, ritmos variados, permitindo a emergência de uma verdade que não se pode mais mascarar. Há o rompimento radical do raciocíni logico, produzindo a dissonância, ou seja, a presença da contradição que ativa e expande a sensibilidade. Assim o teatro não e mais a simulação realista ou estilizada de uma ação, mas um ato de absoluta sinceridade, no qual o mais importante é a relação entre os seres humanos, determinada por uma cena dos sentidos em que proximidade fisica, os olhares, respiração e o suor têm participação ativa, e para o Atuador, uma grande e única oportunidade de entrega total. A busca desse ator renovado deve ser alcançada em função de um teatro comprometido eticamente com o público. A pesquisa temática é tão profunda, quanto a pesquisa estètica. A "tribo" de Atuadores Oi Nois Aqui Traveiz acredita que o teatro precisa se um momento de encontro entre as pessoas, de muita intensidade na vida, do qual se saia potencializado. E para isso, é necessário atuar como se fosse a última vez que se tivesse algo a comunicar aos demais (Tribo de Atuadores, 2002).

Como é possível observar, o atuador, componente do grupo, tem mais funções que atuar. É também um ativista político, no sentido de que, a partir de seu trabalho artístico, ambiciona mobilizar a sociedade, "percebendo como urgente e

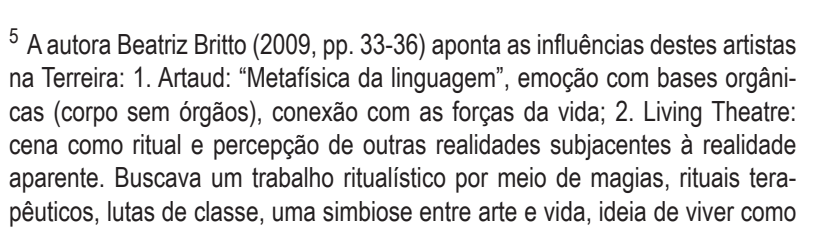

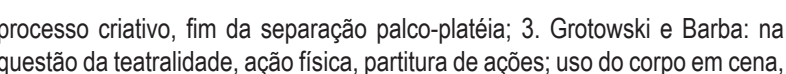

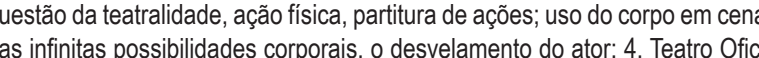

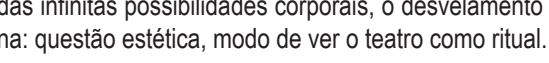

primeira, a transformação de si mesmo", para que, a partir de seu posicionamento de seu próprio questionamento ético, possa criar e pensar um "teatro comprometido eticamente com o público" em que o mais importante é a relação entre todos. Desde a utilização do termo pelo Oficina, já descrito acima, bem como nessas poucas palavras da Tribo de Atuadores, já é possível aproximar as ações éticas e estéticas que norteiam a ação dos atuadores, do conceito que o russo Mikhail Bakhktin ${ }^{6}$ (1895-1975) chama de Ato Responsável. Conceito desenvolvido na década de 1920, o ato responsável (postupok) é um ato de pensamento, de sentimento de desejo, de fala ou de qualquer ação que uma pessoa assume diante do mundo, de uma situação, de um acontecimento, ou mesmo da própria vida. Contudo, não implica simplesmente em agir ou fazer, pensar, sentir, desejar, falar, ou seja, não se encerra apenas em ações. O ato responsável é invocação e invoca, é proposição e é proposta, um posicionamento, uma atitude mesmo que interna ou assumida apenas na consciência pelo indivíduo que se sente instigado, mobilizado, provocado pelas situações cotidianas, pela sociedade e, diante da afronta, aceita, repudia ou toma qualquer outra atitude, até que se torne um dever. Mas esse dever não é simplesmente responsável no sentido ético, moral ou uma responsabilidade que a pessoa assume diante de uma situação, sendo necessário corrigir ou resolvê-la. Para Bakhtin, o ato é responsável no sentido de responsivo também: "compreensão responsiva que salienta a conexão entre compreensão e escuta, escuta que fala que responde, mesmo que não imediata e diretamente; por meio da compreensão e 'pensamento participante' ucastnoe myslenie" (Bakhtin, 2010, p. 11). Portanto, o indivíduo deve responder, de forma responsável ou não, de forma correta ou não, mas de qualquer maneira, contesta, replica, age. O indivíduo aceita, assume a obrigação de agir, de aceitar, de parar, mas não como alguém que é coagido ou que não questiona o que faz. Reage como alguém que acredita que contribui ao evento, à arquitetônica ${ }^{7}$, ao mundo ou às demais pessoas como o único que pode realizar tal ato. $O$ ato responsável, portanto, é uma resposta, uma reação que, como dever, é assumida, aceita pelo indivíduo porque é única, singular, peculiar. Só ele pode realizá-la e ao fazê-la, afirma a sua existência única no mundo, funda a sua presença, se torna real no mundo. Não que as outras pessoas não possam fazê-lo, mas cada uma faria diferente da outra e todos os atos seriam, igualmente, únicos e singulares.

[...] é, ao mesmo tempo, ser e dever: eu sou real, insubstituível e é por isso que preciso realizar a minha singularidade peculiar. [...] eu não posso nem seque por um momento não ser participante da vida real, inevitável e necessariamente (nuditel'no) singular; eu preciso ter um dever meu (dolzhenstvovanie); em relação ao todo, seja o que for e em que condição me seja dada, eu preciso agir a partir do meu lugar único, mesmo que se trate de um agir internamente (Bakhtin, 2010, p. 98)

Autor conhecido no Ocidente a partir da década de 1960 como critico literá to ffilologo. Bakhtin escreveu algumas obras no início do sécullo XX, hoje muli
conhecidas, como Marxismo e Filosofia da Linguagem, Cultura Popular Idade Média: o contexto de François Rabelais, Estetitica da Criação Verbal Problemas da poetica de Dostoievski, que trazem inumeros conceitos discltyais pode-se citar dialogismo, polifonia, exotopia e etc

Arquitetênica é um termo também usado pelo filísofó prussiano Kant (1724
804). Contudo, Bakhtin pensa a estrutura arcuitetônica do mundo, ou seja, a

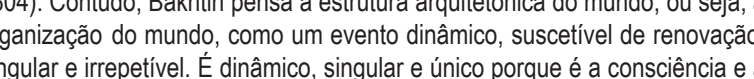

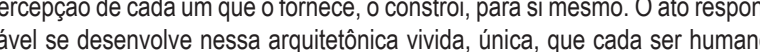
vê, ouve, sente e pensa (Ponzio in Bakhtin, 2010, p. p. 16: 111--140)

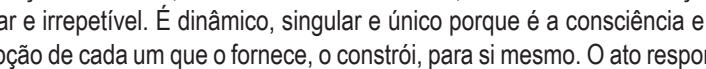


Deste modo, o ato responsável pode ser considerado como um ato realizado por alguém, como resposta a alguma necessidade ou questão do mundo. Ao realizar esse ato ela aceita o dever de participar e contribuir porque acredita que sua singularidade, sua importância, sua existência é única e fundamental. Uma vez consciente de seu dever, entra no evento do existir ${ }^{8}$, porque, somente como ser participante da vida, realizadora de atos responsáveis, que se torna consciente dela, de si mesma dos outros. É apenas no interior do ato que a vida e a existência fazem sentido e completa o seu ciclo. O indivíduo contaminado de sua singularidade, de sua importância de seu dever, se depara com o seu fator emotivo-volitivo ${ }^{9}$. É esse fator o fundante da realidade, da verdade e da relação humana para com o mundo. Verdade (pravda) como entonação do ato, como a sua afirmação, como aquilo que o singulariza, que torna único, a sua marca. Toda e qualquer relação, avaliação, reconhecimento, diálogo com o outro no mundo, deve ser feito a partir do interior do ato, justamente por causa do acesso ao emotivo-volitivo que firmará a sua contribuição única, selará sua participação e marcará a verdade do ato na realidade.

Como é possível observar, o ato responsável não é necessariamente um ato político ou um dever cívico que o cidadão assume no mundo, mas ao mesmo tempo, é quase impossível desvinculá-los. Em algum momento, esse indivíduo consciente e atuante, de alguma forma e em algum momento, irá circunscrever-se com atos políticos. Portanto, o atuador da "tribo" se insere perfeitamente neste perfil porque primeiramente, como artista, assume a importância de seu posicionamento diante da sociedade, valoriza a sua ação artística como única e necessária à construção do mundo. $O$ atuador é um ativista político-artístico que percebe a necessidade de transformar a si mesmo, de assumir um posicionamento como artista que não se restringe ao palco. Os seus "atos responsáveis" vão além da atuação, abraçando a sociedade como um todo, cujas ações se desdobram, principalmente, na direção e pedagogia dos projetos sociais espalhados pela periferia de Porto Alegre.

A pesquisadora Beatriz Britto (2009, p. 19) nomeia a "tribo de atuadores" como um coletivo de resistência contra os problemas sociais da sociedade brasileira e gaúcha, contra o sistema capitalista, as estruturas de dominação como a política e a ação jornalística que, com suas críticas, seu poder de persuasão e estratégias, cria um fenômeno que a autora chama de "homogeneização do pensamento". A "tribo" adota uma postura transgressora de forma a romper com as estruturas do sistema econômico, politico e social, assim como o teatral, desde o nome Tribo de Atuadores Ói Nóis Aqui Traveiz. Embora faça teatro, se autodenomina "tribo de atuadores" e o espaço que utiliza para trabalhar é denominado "Terreira". Pensa sua organização de grupo como uma tribo indígena em que todos são importantes, como uma grande família. Terreira porque concebem o seu espaço com outro juízo de valor, transformando-o simbolicamente como sagrado (Alencar, 1997, p. 80). Ói Nóis Aqui Traveiz

é o nome da música composta por Geraldo Blota (1925-2009) e Lourival Peixoto, imortalizada por Adoniran Barbosa (1910-1982), escolhida porque não segue as regras gramaticais e com isso, assume um ato que valoriza e homenageia o popular, 0 povo, a comunidade se comprometendo com ela.

O atuador participa de todas as etapas do processo artístico, idealiza em grupo o que a "tribo" chama de teatro "comprometido com o público", abarcando, primeiramente, todos os integrantes. A criação dramatúrgica e cênica é pensada como uma celebração na qual arte e vida se fundem, e se torna um espaço de comunhão, de compartilhamento de experiências pessoais e artísticas, de modo que proporcione ao espectador uma experiência real, afetando diretamente os seus sentidos e estimulando-o a se tornar participante dela. Para criar esta cena "cerimônia" que mobiliza e convida o público a comungar com a "tribo", o atuador tem uma preparação que exclui a máscara ${ }^{10}$, para que assim, possa manter uma relação de comunicação direta com o público. Por isso, também não usa a palavra personagem, mas persona. Não usar máscaras e compor personas, implica que todo material é criado a partir da vivência do próprio atuador, daquilo que é mais essencial da sua personalidade e de seu ato artístico, explorando por meio de exercícios físico-vocais, toda sua fisicalidade, expondo toda a sua materialidade corporal. E assim em evidência, se revela, se coloca, se disponibiliza para o ato artístico em toda a sua potência, como o realizador de "atos responsáveis" descrito por Bakhtin.

O atuador, ao contrário de algumas manifestações teatrais que reinaram até a segunda metade do século XX, não representa, mas presentifica, ou seja, vive uma experiência no momento presente, aberta aos imprevistos, ao fluxo da vida, ao "aqui -agora". O ato, a ação teatral é substituída pelo "ato ritual", ato criativo que busca transformar a realidade da consciência e corpo do atuador, de forma a também transformar o ambiente social do público. Por isso, as cenas-ritos da "tribo" são intimistas, implicam numa proximidade física entre atuadores e espectadores, sem poupá-los dos olhares, da respiração, do suor, da "materialidade da voz, do gesto, da destilação das ações, da dilatação da presença do atuador" (Britto, 2008, p. 89-90). Isso implica que o público participe da cena, mesmo que apenas como observador. Desde o "te-ato" é que o atuador é colocado como responsável pela direção, criação de todo o trabalho artístico, valorizando a postura ética e responsável, a comunicação direta, sem máscaras, sem personagens até que o público seja contaminado e, mesmo que indiretamente, se torne participante da cena, do ato teatral. Este "papel" assumido pelo público é fundamental para compreender o ato responsável, não apenas como uma tomada de postura, mas como resposta ao que se está propondo no tempo e espaço teatral. Este deslocamento de papéis, este diálogo, esta comunhão, proporcionam, primeiramente, uma ação entre iguais, que gera uma tomada de decisão, um posicionamento não só dos atores, mas também do público. Portanto, todos se 
tornam responsáveis pelo acontecimento teatral, ao menos no tempo e no espaço no qual acontece. O público tem a possibilidade de se posicionar, questionar, gostar ou não do que se discute e talvez, levar esta conduta à vida. A "tribo" espera que ele seja mobilizado o suficiente para mantê-la cotidianamente. Portanto, o atuador, não é apenas um realizador de atos responsáveis, mas também um provocador deles.

Para a composição desta "cena cerimônia", da persona, do "ato ritual", a formação do atuador é diferenciada. Todo atuador estudante passa por um "ritual de passagem" no qual cria uma cena/ritual da sua persona e a apresenta ao grupo no final de sua formação. A construção do espetáculo também é feita a partir de rituais que cada ato apresenta de sua persona. O atuador deve gestá-la como a um filho, se preocupando com tudo: voz, gesto, música, cenário, adereço cênico, luz, figurino, relação com o espaço, cheiro, texto, cores, relação com o público etc. É por meio do ritual e de uma ideia de "transe ${ }^{11 "}$ que o atuador encontra a entrega, a teatralização, o dispêndio absoluto, o corpo inteiro e livre, o rompimento do raciocínio lógico e a expansão da sensibilidade. O ritual é marcado pela preocupação da "tribo" de não racionalizar o trabalho por isso, um dos principais recursos de criação que utiliza é a improvisação. O improviso, individual, em dupla, em grupos, com e sem texto, luz, figurino e objetos aliado às ações que se repetem e à música minimalista, ajuda o ator a "entrar neste transe" e conceber cenas livres da racionalização, com organicidade e entrega total do atuador. da ativação de um fluxo e da relação/contato com o outro, que propicie um outro estado perceptivo, com a emergência de associações livres e de impulsos corporais que possam dar forma ao gesto e à voz; as ações afloram então, como resultado de um fluxo inconsciente, durante o devir da performance, linha de fuga criadora, que escape aos codigos e padrões pré-estabelecidos de linguagem. Existe uma etapa preparatória ao processo de improvisação como o aquecimento energético que mobilize diferentes partes do corpo, exercícios de correspondencia entre corpo voz, jogos de interaça de grupo, etc. Éstinulos sensoriais são utilizados tambén durante o processo, cono uns da música que exeça um efeito hipnótico sobre objetos capazes de despertar associaç̃̃es como o pano, o bastão, rede; fragmentos de textos, etc. Os improvisos podiam ser com ou sem fa bastas mutas vezes eram usados para reescrever o texto original da peça (Britto, 2008, pp. 89-90).

Bakhtin não descreve um ato não responsável, não coloca quando um ato deixa de ser responsável, mas expõe quando ele enfraquece. $O$ enfraquecimento acontece quando o sujeito não assume a sua particularidade individual nem do outro, no mundo. Não reconhece o seu dever, a sua singular e fundamental participação. Para esse sujeito, tudo é igual, não reconhece as diferenças, os valores, os pesos, tudo fica no plano geral e, portanto, perde o seu comprometimento com a vida porque, para o autor, a sua existência é marcada pelo reconhecimento de que cada pessoa é única no mundo, de que cada ação é fundamental. Sem isso, o ato enfraquece e o indivíduo não participa do mundo, anula sua singularidade. O improviso, pensar a cena como ritual, explorar a ideia de transe pelo atuador, como a construção de uma consciência

列 unica, sua potência de existir como artista com um papel muito claro na sociedade: a de criar uma arte que mobiliza os espectadores a partir da entrega total de seu ser. Portanto, a formação do atuador tem a preocupação de não permitir que o ato artístico se enfraqueça, que ele seja sempre um meio de mobilizar, instigar, transformar o público e a realidade social.

Ao dissertar sobre o ato responsável, Bakhtin expõe a dificuldade de falar sobre o conceito porque, para ele, qualquer ciência ou modalidade é incapaz de se aproximar do ato responsável e, desse modo, mais difícil ainda é atingir a sua essência. $O$ ato responsável é composto por seu conteúdo-sentido ${ }^{12}$ e pela sua presença (pela sua particicircunstâncias). Essas duas estruturas são inseparáveis embora acarretem funções diferentes. A primeira trata de seu juízo universal, enquanto que a segunda abarca a existênliar, explicar o ato responsável de modo que contemple a sua essência ou a sua verdade (pravda), deve ser feito a partir da experiência do ato, da sua realização-existência que biologia, a sociologia, a estética ou a historiografia seriam capazes de realizar tal proeza porque não foram capazes de atingir este momento único do existir-evento, ficando apenas no âmbito do conteúdo-sentido, sustentando teorias e proposições gerais que defendem o senso comum e o coletivo, mantendo seus argumentos no plano geral, excluindo o fundamental e cometendo o maior erro: abandonam e anulam o humano e $o$ ato como singular, único, particular. Para Bakhtin, as artes e a linguagem seriam possibilidades de quebrar esta dificuldade, porque as suas estruturas sempre estiveram a serviço de atos individuais, valorizando os esforços únicos. No caso do trabalho da "terreira", isso é possível devido a sua estrutura e pesquisa, o posicionamento político que os atuadores adotam dentro e fora da cena; o reconhecimento do olhar cuidadoso para com a sociedade e da importância de seu trabalho dentro dela; o desenvolvimento de uma pesquisa coletiva na qual todos estão envolvidos em todas as etapas sem hierarquias; a preocupação com uma formação teatral cujo plano pedagógico não está preocupado apenas com a formação artística, mas também com a formação cidadã dos participantes; o repensar, rediscutir, deslocar para ir além, nos próprios conceitos teatrais de modo a romper com o raciocínio lógico, com o discurso pronto buscando uma presença que atinja a sensibilidade do espectador; a busca pelo contato com público de modo que seja sincero, que prevaleça a relação entre os seres humanos, que os impulsione, os potencialize e os distinga. Todo este conjunto de ações mostra a proximidade entre o ato responsável do ato ritual, da postura do atuador.

A riqueza, a pesquisa e a potência do trabalho estético da Ói Nóis Aqui Traveis é uma possibilidade de que o ato responsável e o pensamento político não sejam utopias, atos ingênuos ou posturas datadas de um período passado. A atitude provocativa do atuador que nasceu num período de questionamentos e necessidades do 
momento histórico, social e comportamental pelo qual o Brasil passava na década de 1970, segue pulsante e em desenvolvimento até hoje. Os seus trabalhos continuam sendo espaços para cumprir o dever artístico-cidadão como atos responsivos, criativos e artísticos aos acontecimentos do mundo e, ao mesmo tempo, de responsabilidade para com o público. Como declara a persona Kassandra ${ }^{13}$, no espetáculo de 2001, Aos que Virão Depois de Nós, Kassandra in process:

Kassandra: Há demasiado sangue. Há demasiada violência. Os que amam verdadeiramente a justiça não têm direito ao amor. Estão erguidos como eu. Com a cabeça levantada, os olhos fixos. O que faria o amor nessas almas orgulhosas? O amor, Enéias, baixa docemente as cabeças. Mas conosco não é possível. Temos um pescoço demasiado rígido.

\section{Referências}

ALENCAR, Sandra. Atuadores da Paixão. Porto Alegre: FUMPROARTE,1997.

BAKHTIN, Mikhail. Para Uma Filosofia do Ato Responsável. São Carlos: Pedro \& João Editores, 2010.

BRITTO, Beatriz. Uma Tribo Nômade: a ação do Ói Nóis Aqui Traveiz como espaço de resistência. Porto Alegre: Terreira da Tribo, 2009. 2. ed.

PAVIS, Patrice. Dicionário de Teatro. São Paulo: Perspectiva, 1999.

PONZIO in BAKHTIN. Para Uma Filosofia do Ato Responsável. São Carlos: Pedro \& João Editores, 2010.

SANTOS, Valmir. (org) Aos que Virão Depois de Nós, Kassandra in process: a criação do horror. Porto Alegre: Tomo Editorial, 2002. 2. ed.

SILVA, Armando Sérgio da. Oficina: do teatro ao te-ato. São Paulo: Perspectiva, 1981.

TOLEDO, Magdalena Sophia Ribeiro. Antropologia e Teatro: o grupo oi nóis aqui traveiz e $(\mathrm{m})$ "Kassandra in process". Florianópolis 2007. Universidade Federal de Santa Catarina. Centro de Filosofia e Ciências Humanas. Programa de Pós-graduação em Antropologia Social.

TRIBO DE ATUADORES ÓI NÓIS AQUI TRAVEIZ. Aos que Virão Depois de Nós, Kassandra in process: a criação do horror. Porto Alegre: 2002. DVD. 65 min.

http://www.grupotempo.com.br/tex_aos_atores.html

Recebido em 21/04/2014

Aprovado em 26/06/2014

3 Em 2001, o grupo Ói Nóis Aqui Traveiz estreou Kassandra in

Process, inspirado no romance da escritora alemã Christa Wolf. 